\title{
Lipocytes from Normal Rat Liver Release a Neutral Metalloproteinase that Degrades Basement Membrane (Type IV) Collagen
}

\author{
Michael J. P. Arthur, Scott L. Friedman, F. Joseph Roll, and D. Montgomery Bissell \\ The Liver Core Center and Medical Service, San Francisco General Hospital, and Department of Medicine, \\ University of California, San Francisco, California 94143
}

\begin{abstract}
We report a proteinase that degrades basement-membrane (type IV) collagen and is produced by the liver. Its cellular source is lipocytes (fat-storing or Ito cells). Lipocytes were isolated from normal rat liver and established in primary culture. The cells synthesize and secrete a neutral proteinase, which by gelatin-substrate gel electrophoresis and gel filtration chromatography, has a molecular mass of 65,000 D. The enzyme is secreted in latent form and is activated by p-aminophenylmercuric acetate but not by trypsin. Enzyme activity in the presence of EDTA is restored selectively by zinc and is unaffected by serine-protease inhibitors. In assays with radiolabeled soluble substrates, it degrades native type IV (basement membrane) collagen but not interstitial collagen types I or $V$ and exhibits no activity against laminin or casein. At temperatures causing partial denaturation of soluble collagen in vitro, it rapidly degrades types $I$ and $V$. Thus, it is both a type IV collagenase and gelatinase. The enzyme may play a role in initiating breakdown of the subendothelial matrix in the Disse space as well as augmenting the effects of collagenases that attack native interstitial collagen.
\end{abstract}

\section{Introduction}

Basement membrane is a specialized form of extracellular matrix underlying the epithelium and endothelium of parenchymal tissues with important biologic effects on adjacent cells. It consists of a complex of type IV collagen, large glycoproteins (laminin, entactin), and proteoglycan $(1,2)$. Introduced into culture as the substratum, matrix of this type exerts major effects on the morphology and cell-specific function of mesenchymal and epithelial cells, including those in the liver (3-6). In vivo alteration or replacement of the basement membrane may be an important cause of epithelial dysfunction. Prominent among the effects of inflammation in the liver is deposition of a neomatrix in place of the normal basement membrane-like matrix in the subendothelial (Disse) space. This

A preliminary report of this work has been published as an abstract (1988. Hepatology [Baltimore]. 8:1228 [Abstr.]).

Dr. Arthur's present address is Department of Medicine II, LD68, South Laboratory and Pathology Block, Southampton General Hospital, Tremona Road, Southampton S09 4XY, UK. Address reprint requests to Dr. D. M. Bissell, Liver Center Laboratory, Building 40, Room 4102, San Francisco General Hospital, San Francisco, CA 94110.

Received for publication 9 November 1988 and in revised form 16 May 1989.

J. Clin. Invest.

(C) The American Society for Clinical Investigation, Inc.

$0021-9738 / 89 / 10 / 1076 / 10 \$ 2.00$

Volume 84, October 1989, 1076-1085 change, termed capillarization (7), correlates with clinically manifest liver disease (8).

Collagenase activity is generally increased during the early stage of liver injury $(9,10)$, suggesting that matrix degradation plays a role in the fibrosing process. These findings have stimulated new interest in mechanisms of matrix turnover, both normal and pathologic. Polymorphonuclear leukocytes contain collagenases and other proteinases that may be released at sites of inflammation (11). A number of mesenchymal cell types also secrete matrix proteinases, suggesting possible sources of these enzymes within parenchymal tissues. Included are metalloproteinases with gelatinase specificity with activity in vitro against denatured collagen. Limited digestion (by a specific collagenase) may cause unfolding sufficient to render the native collagen helix susceptible to gelatinase, which completes the degradation process.

The role of matrix proteinases originating within liver is poorly understood. Most studies have been performed with whole-liver homogenate, and the results are widely divergent $(9,10,12-16)$. Although studies with isolated, cultured cells are reported (17-22), those of nonparenchymal cells have used mixed isolates containing sinusoidal endothelial cells, Kupffer cells, and lipocytes in indeterminate proportions. Precise information as to cellular sources of matrix proteinases in the liver is limited.

Lipocytes have attracted particular attention, because they are within the space of Disse, positioned to exert major effects on matrix metabolism. Virtually pure isolates can be prepared from normal rat liver and established in culture (23) where they elaborate relatively large amounts of matrix proteins (24-26). This work demonstrates that, in addition, they mediate matrix turnover, producing a neutral metalloproteinase with activity against native type IV (basement-membrane) collagen as well as activity against partially denatured collagens I and V.

\section{Methods}

\section{Materials}

Pronase was obtained from Calbiochem-Behring Corp. (La Jolla, CA) and collagenase (type I) from Worthington Biochemical Corp. (Freehold, NJ). Arabinogalactan (Larex-Lo) was purchased from Larex International (Tacoma, WA). Calf and horse serum were purchased from Flow Laboratories, Inc. (McLean, VA). Acetic anhydride (CFA 339; $106 \mathrm{mCi} / \mathrm{mmol}$ ) and Amplify were obtained from Amersham Corp. (Arlington Heights, IL), and Bolton-Hunter reagent (NEX 120) from Dupont/New England Nuclear, Inc. (Boston, MA). Sephacryl S200 Superfine and S1000 Superfine were purchased from Pharmacia Fine Chemicals, Inc. (Piscataway, NJ). Lactoperoxidase (from bovine milk), gelatin (type III, from calf skin), casein, $p$-aminophenyl mercuric acetate (APMA), ${ }^{1}$ and soybean trypsin inhibitor (type I-S) were purchased

1. Abbreviations used in this paper: APMA, p-aminophenyl mercuric acetate; EHS, Engelbreth-Holm-Swarm; NEM, $N$-ethylmaleimide. 

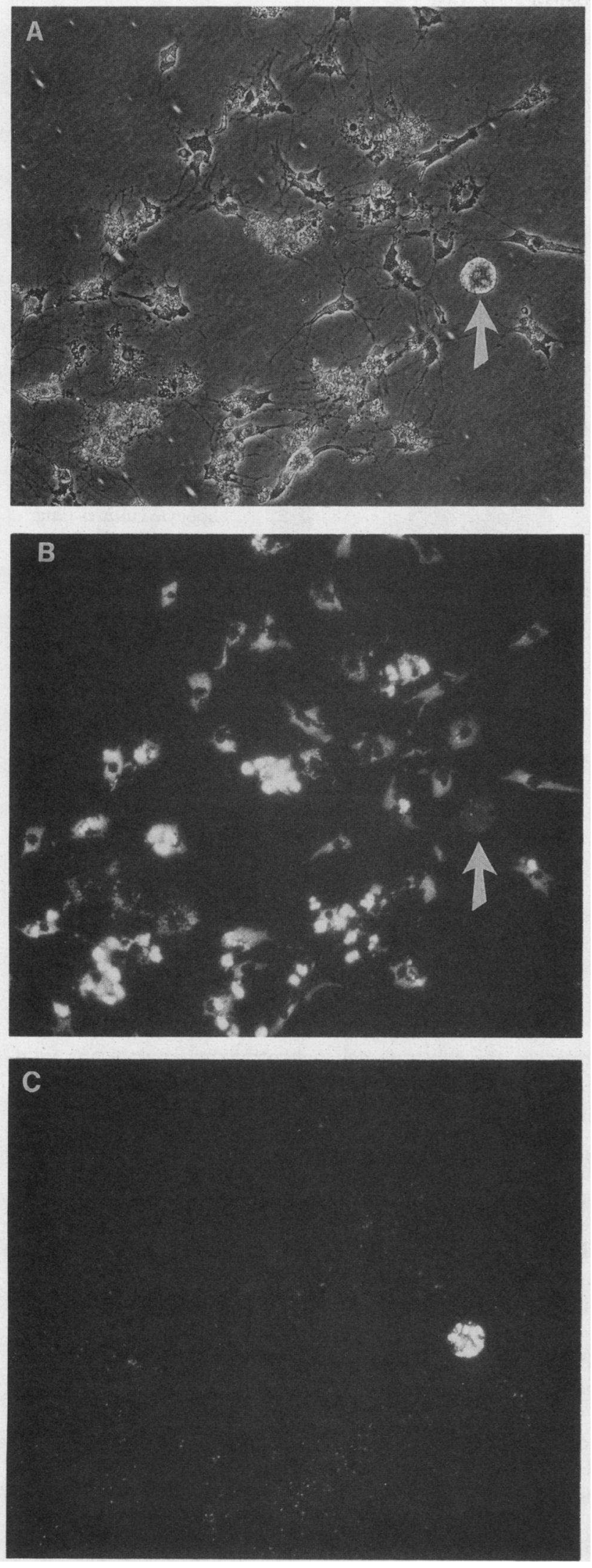

Figure 1. Identification of lipocytes and Kupffer cells in culture. Lipocytes were isolated and purified from normal rat liver, as described in Methods. The cells were cultured for $3 \mathrm{~d}$ and then incubated for 30 min with heat-killed, FITC-labeled Staphylococci, which are ingested by Kupffer cells only (23). After washes to remove free Staph- from Sigma Chemical Co. (St. Louis, MO), and TPCK-trypsin from Cooper Biomedical, Inc. (Malvern, PA). Ecolume was obtained from ICN Radiochemicals, Inc. (Irvine, CA).

\section{Cell isolation and culture}

Lipocytes and Kupffer cells were isolated from normal rat liver (male Sprague Dawley rats, $450-600 \mathrm{~g}$ ) by a combination of pronase and collagenase perfusion and purified by arabinogalactan density gradient centrifugation as described (23), with modifications. Primary lipocyte cultures were prepared from cells that were buoyant on $6 \%$ arabinogalactan and from cells at the interface between 6 and $8 \%$ arabinogalactan. Cells from the $8 \% / 12 \%$ and $12 \% / 15 \%$ arabinogalactan interfaces were pooled for purification of Kupffer cells by centrifugal elutriation $(27,28)$. Primary cultures of lipocytes and Kupffer cells were plated in 35-mm plastic tissue culture plates and maintained in medium 199 (28) supplemented with $10 \%$ calf and $10 \%$ horse serum, 4 $\mathrm{mU} / \mathrm{ml}$ insulin, $10^{-6} \mathrm{M}$ corticosterone and $100 \mathrm{U} / \mathrm{ml}$ penicillin. Media were changed daily.

Cell purity was assessed after $48-72 \mathrm{~h}$ in primary culture, by phase-contrast microscopy, intrinsic vitamin A fluorescence to identify lipocytes (23), and uptake of FITC-conjugated Staphylococci to identify Kupffer cells (23) (Fig. 1). Lipocyte cultures prepared from cells that were buoyant on $6 \%$ arabinogalactan were highly purified, containing $<0.1 \%$ Kupffer cells as contaminants. Lipocyte cultures prepared from cells at the 6-8\% Stractan interface contained $<2 \%$ Kupffer cells as contaminants. Kupffer cell cultures were $\sim 90 \%$ pure, with lipocytes as the principal contaminant.

\section{Preparation of matrix-protein substrates}

Acid-soluble type I collagen was extracted and purified from rat skin and radiolabeled with $\left[{ }^{14} \mathrm{C}\right]$ acetic anhydride according to the method of Cawston and Barrett (29). Radiolabeled type I collagen $(5 \mathrm{mg} / \mathrm{ml}$ in $0.05 \mathrm{M}$ acetic acid) was stored at $-20^{\circ} \mathrm{C}$. Before use, this was diluted to $2 \mathrm{mg} / \mathrm{ml}$ in $0.05 \mathrm{M}$ acetic acid and dialyzed, at $4^{\circ} \mathrm{C}$, against $0.05 \mathrm{M}$ Tris, $\mathrm{pH} 7.6,0.2 \mathrm{M} \mathrm{NaCl}, 0.02 \% \mathrm{NaN}_{3}$. Type $\mathrm{V}$ collagen was extracted and purified from pepsin-treated human placental amniotic membrane by the method of Burgeson et al. (30), with the exception that it was precipitated by dialysis against distilled water as described by Madri and Furthmayr (31). This preparation, which contained a small amount of residual type I collagen, was iodinated using the BoltonHunter reagent by the method of Roll et al. (32), and stored at $4^{\circ} \mathrm{C}$ in $0.05 \mathrm{M}$ acetic acid. Type IV collagen was extracted from EngelbrethHolm-Swarm (EHS) murine sarcoma by the method of Kleinman et al. (33). Type IV collagen was purified by differential salt precipitation and DEAE-cellulose chromatography and iodinated as described by Yurchenco and Furthmayr (34), with the exception that, for final purification, iodinated type IV collagen was dialyzed against $2 \mathrm{M}$ guanidine, $0.05 \mathrm{M}$ Tris, pH 7.4, $2 \mathrm{mM}$ DTT, $5 \mathrm{mM}$ EDTA, $2 \mathrm{mM}$ $N$-ethylmaleimide (NEM), $0.1 \mathrm{mM}$ PMSF and chromatographed, in this buffer, on a Sephacryl $\$ 1000$ superfine column $(1 \times 95 \mathrm{~cm})$. Storage of iodinated type IV collagen was at $4^{\circ} \mathrm{C}$ in the same buffer. Immediately before use, radiolabeled type IV and type $\mathrm{V}$ collagens were dialyzed against $0.05 \mathrm{M}$ Tris, $\mathrm{pH} 7.6,0.2 \mathrm{M} \mathrm{NaCl}, 10 \mathrm{mM} \mathrm{CaCl}$, $0.02 \% \mathrm{NaN}_{3}$, and $0.05 \%$ Brij 35. Laminin was prepared from murine EHS sarcoma as described (25).

\section{Assessment of released proteinase activities}

Lipocytes or Kupffer cells, cultured for $72 \mathrm{~h}$, were washed to remove serum and incubated in serum-free medium 199. Media were har-

ylococci, cultures were examined by phase-contrast microscopy (Fig. $1 A)$, and by fluorescence microscopy under either UV (365 nm) excitation (Fig. $1 B$ ) or blue $(495 \mathrm{~nm})$ excitation (Fig. $1 C$ ). The intrinsic fluorescence of the vitamin A-containing lipocytes is evident in Fig. $1 B$. Blue excitation for FITC shows that one cell in the field is a Kupffer cell (Fig. $1 C$ ). The same cell in Fig. $1, A$ and $B$ is indicated by an arrow. 
vested after $48 \mathrm{~h}$ and clarified by centrifugation before analysis of released proteinase activities.

Substrate gel analysis. Proteinase activities in crude, unconcentrated, Kupffer cell or lipocyte-conditioned media were visualized by gelatin-substrate SDS-PAGE, as described by Herron et al. (35). For some experiments, casein $(1 \mathrm{mg} / \mathrm{ml}$ in distilled water) or laminin (1 $\mathrm{mg} / \mathrm{ml}$ in $0.2 \mathrm{M}$ ammonium bicarbonate), rather than gelatin, were incorporated as substrates in SDS-polyacrylamide gels.

Quantitative analysis of gelatin-degrading activity. Kupffer cell or lipocyte-conditioned media were dialyzed against sample buffer $(0.05$ M Tris, pH 7.6, $0.2 \mathrm{M} \mathrm{NaCl}, 10 \mathrm{mM} \mathrm{CaCl}_{2}$, and $0.02 \% \mathrm{NaN}_{3}$ ) for quantitative assay of gelatin-degrading activity by the method of Harris and Krane (36), with modifications. Rat skin $\left[{ }^{14} \mathrm{C}\right]$ type I collagen, (2 $\mathrm{mg} / \mathrm{ml}$ in $0.05 \mathrm{M}$ Tris, $\mathrm{pH} 7.6,0.2 \mathrm{M} \mathrm{NaCl}$, and $0.02 \% \mathrm{NaN}_{3}$ ) was heat denatured at $60^{\circ} \mathrm{C}$ for $20 \mathrm{~min}$, immediately before use, to form $\left[{ }^{14} \mathrm{C}\right]-$ gelatin. $50 \mu \mathrm{l}$ of this preparation were incubated, in triplicate, with 100 $\mu l$ of sample for $16 \mathrm{~h}$ at $37^{\circ} \mathrm{C}$ in microcentrifuge tubes. At the end of the incubation, $50 \mu \mathrm{l}$ of cold gelatin $(3 \mathrm{mg} / \mathrm{ml})$ were added and nondegraded substrate precipitated by addition of $50 \mu \mathrm{l}$ of $100 \%$ (wt/vol) TCA. Tubes were placed on ice for $30 \mathrm{~min}$, microcentrifuged at $4^{\circ} \mathrm{C}$ for $15 \mathrm{~min}$, and $200 \mu \mathrm{l}$ of supernatant counted in $5 \mathrm{ml}$ Ecolume by scintillation spectrometry. Samples were assayed nonactivated or, where indicated, after treatment with APMA $(1 \mathrm{mM} \times 60 \mathrm{~min}$ at $\left.37^{\circ} \mathrm{C}\right)$ or TPCK-trypsin $\left(1-100 \mu \mathrm{g} / \mathrm{ml}\right.$ for $60 \mathrm{~min}$ at $\left.37^{\circ} \mathrm{C}\right)$ followed by addition of a fivefold molar excess of soybean trypsin inhibitor (STI). Controls contained sample buffer, either alone or with addition of either APMA or trypsin/STI.

By this method, gelatin degradation was linear over $16 \mathrm{~h}(r=0.999)$ and the coefficient of variation for 10 replicate samples was $4.3 \%$. 1 $\mathrm{mU}$ of gelatinase activity is defined as degradation of $1 \mathrm{ng}$ of gelatin per minute. Data were expressed per microgram cellular DNA, measured by a fluorometric technique (37).

\section{$S D S-P A G E$}

SDS-PAGE was performed on vertical slab gels according to the method of Laemmli (38). Gels were stained with $0.1 \%$ Coomassie blue in $50 \%$ methanol, $10 \%$ acetic acid (vol/vol), destained in $5 \%$ methanol, $7.5 \%$ acetic acid (vol/vol), and washed in distilled water. Gels containing ${ }^{14} \mathrm{C}$-labeled substrates were soaked in Amplify for 20 min before drying. For autoradiography, dried gels were placed on Kodak X-Omat $\mathrm{S}$ film with a screen for $24-72 \mathrm{~h}$ at $-70^{\circ} \mathrm{C}$.

\section{Results}

Substrate gel analysis of lipocyte-conditioned media. When analyzed by gelatin-substrate SDS-PAGE, the medium from hepatic lipocytes (fat-storing or Ito cells) contained a single band of gelatin-degrading activity, $M_{\mathrm{r}} 65 \mathrm{kD}$ (Fig. $2 A$, lane 1 ). This activity was present in unconcentrated crude media from pure lipocyte cultures (Fig. $2 A$ ) (obtained by culturing cells that were buoyant on $6 \%$ arabinogalactan) and was the only gelatin-degrading activity both in those cultures and in cultures containing $<2 \%$ Kupffer cells as contaminants (not shown). Its release was markedly decreased in the presence of cycloheximide (Fig. $2 A$, lane 2 ) and thus requires ongoing protein synthesis. Kupffer cell cultures $(\sim 90 \%$ pure, with lipocytes as contaminants) released a higher molecular weight gelatin-degrading activity, $M_{\mathrm{r}} 95 \mathrm{kD}$ (Fig. $2 \mathrm{~B}$ ). Relatively low levels of the $65-\mathrm{kD}$ activity also were detectable in media obtained from these cultures, consistent with the degree of lipocyte contamination (Fig. $2 B$ ). Thus, the activity migrating at $65 \mathrm{kD}$ appears to be a product mainly, if not exclusively, of lipocytes. Its substrate range was studied with gels that incorporated laminin or casein in place of gelatin, and no activity was detected (Fig. $2 C$ ). The activity was inhibited by EDTA

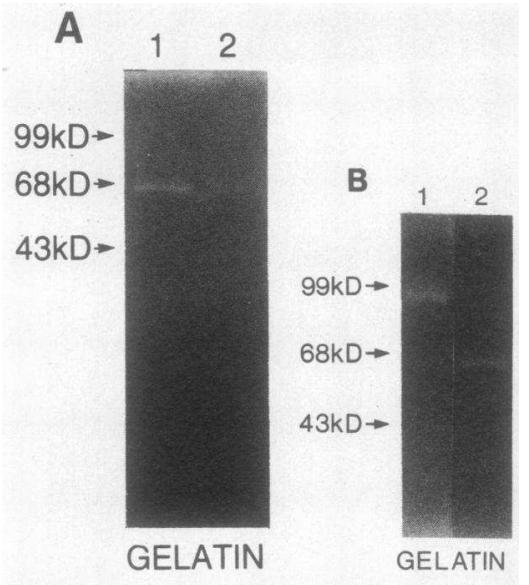

Figure 2. Substrate-gel analysis of culture media. Primary lipocyte cultures (2-3 d old) were maintained in serum-free media for $\mathbf{4 8}$ h. Conditioned media were harvested and analyzed by gelatin-substrate SDS-PAGE as described in Methods. $(A)$ Pure lipocytes were cultured in the absence (lane 1 ) or presence (lane 2) of cycloheximide (5 $\mu \mathrm{g} / \mathrm{nl})$. (B) Conditioned medium from Kupffer cells (lane C
$\substack{99 \mathrm{kD} \rightarrow \\ 68 \mathrm{kD} \rightarrow \\ 43 \mathrm{kD} \rightarrow}$
LAMININ 1) was analyzed in parallel with medium from lipocyte cultures (lane 2). (C) Conditioned media were electrophoresed on gels containing laminin (lanes 1 and 2) or casein (lane 3) as substrate, and otherwise treated as before; lanes

$I$ and 3 , lipocyte-conditioned medium; lane 2, PMA-stimulated human neutrophil-conditioned medium, used as a positive control (degradation of casein by this medium, not shown, was similar to that of laminin). Gelatin-degrading activity in these lipocyte-conditioned media was verified in parallel studies (not shown).

added to the substrate gel incubation buffer, but was unaffected by either PMSF or NEM (Fig. 3). These results indicate that the gelatin-degrading activity is a metalloproteinase.

Quantitative analysis of gelatin-degrading activity released by lipocytes. Gelatin-degrading activity (Table I) was present predominantly as latent proenzyme that was activated by APMA. The measured activity from pure lipocyte cultures (Table I) varied three to fivefold for nonactivated media and up to 20-fold for media activated with APMA. The data from cultures containing Kupffer cells as a minor contaminant ( $<2 \%$ by cell number) varied to the same extent, suggesting that the presence of Kupffer cells did not account for the variation.

Gel filtration of lipocyte-conditioned medium. Lipocyteconditioned medium was chromatographed on a column of Sephacryl S200, with analysis of individual fractions by gelatin-substrate SDS-PAGE and by assay (after treatment with APMA) for gelatin-degrading activity using $\left[{ }^{14} \mathrm{C}\right]$ gelatin as substrate. As shown in Fig. 4, the peak of activity migrated at $65 \mathrm{kD}$. By gelatin substrate SDS-PAGE, the only activity detectable within this peak was the $65-\mathrm{kD}$ proteinase. In other experiments, in which larger volumes of lipocyte-conditioned media were pooled and concentrated, the results of column chromatography were similar. Recovery of gelatin-degrading 


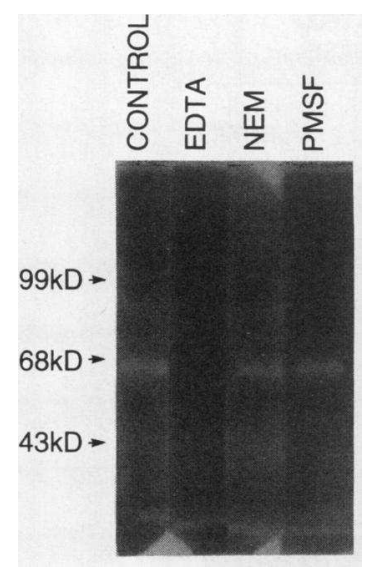

Figure 3. Characterization by substrate-gel of the proteinase activity in lipocyte-conditioned culture media. Media were prepared and harvested as described in Fig. 2. Replicate samples from a single lipocyte preparation were electrophoresed in four lanes of the same gelatin substrate gel. After electrophoresis, individual lanes were excised and incubated in $0.05 \mathrm{M}$ Tris, $\mathrm{pH} 8.0,5 \mathrm{mM} \mathrm{CaCl}_{2}, 0.02 \%$ azide containing no proteinase inhibitors (control), EDTA (10 mM), NEM (2 mM) or PMSF (1 mM) before being fixed and stained.

activity from the column was $100 \%$. The data suggest that lipocytes produce a single proteinase species of $65 \mathrm{kD}$.

Characterization and substrate specificity of partially purified $65-\mathrm{kD}$ proteinase. Fractions containing the $65-\mathrm{kD}$ proteinase from the Sephacryl S200 column were pooled for analysis. The recovered enzyme was almost entirely in a latent form (Table II). It was activated $>70$-fold by APMA but $<2$ fold by trypsin. It was completely inhibited by EDTA, but not by PMSF or NEM (Table III), confirming the results with crude culture media. To assess the metal requirement of the enzyme, EDTA inhibition and its reversibility was examined in detail. The enzyme was markedly sensitive to EDTA, even in the presence of $5 \mathrm{mM}$ calcium (Table IV). Activity was restored by zinc at a molar ratio of 2:1 with respect to EDTA. At a higher molar ratio, the activation was markedly diminished. Partial activation resulted from addition of manganese or copper. The APMA-activated enzyme was completely inhibited also by DTT.

The APMA-activated proteinase was incubated with individual radiolabeled matrix protein substrates, with analysis of reaction products by SDS-PAGE and autoradiography. Degra-

Table I. Release of Degradative Activity against $\left[{ }^{14} \mathrm{C}\right]$ Gelatin by Cultured Lipocytes

\begin{tabular}{lcc}
\hline & \multicolumn{2}{c}{ Gelatinase activity } \\
\cline { 2 - 3 } & Mean & Range \\
\hline Nonactivated & \multicolumn{3}{c}{$m U / \mu g D N A$} \\
APMA-activated & 3.9 & $(1.3-8.1)$ \\
& 12.5 & $(2.3-47.6)$ \\
& $P<0.05$ & \\
\hline
\end{tabular}

Primary cultures of lipocytes were maintained for $72 \mathrm{~h}$ after plating and then transferred to serum-free media for $48 \mathrm{~h}$. Unconcentrated conditioned media were harvested and dialyzed against $0.05 \mathrm{M}$ Tris$\mathrm{HCl}$, pH 7.6, $0.2 \mathrm{M} \mathrm{NaCl}, 10 \mathrm{mM} \mathrm{CaCl}_{2}$, and $0.02 \%$ azide. Gelatinase activity was assayed with heat-denatured $\left(60^{\circ} \mathrm{C} \times 20 \mathrm{~min}\right)$ rat skin $\left[{ }^{14} \mathrm{C}\right]$ type I collagen as substrate $(350 \mathrm{cpm} / \mu \mathrm{g} \mathrm{sp}$ act $)$ as described in Methods, with or without activation (1 mM APMA for 60 min at $\left.37^{\circ} \mathrm{C}\right) .1 \mathrm{mU}$ of gelatinase activity is defined as degradation of $1 \mathrm{ng}$ of gelatin/min. The measured radioactivity averaged 427 cpm for nonactivated and $1,775 \mathrm{cpm}$ for APMA-activated samples. Statistical comparisons were made between nonactivated and APMA-activated samples using the Wilcoxon rank sum test for paired data $(n=5)$.

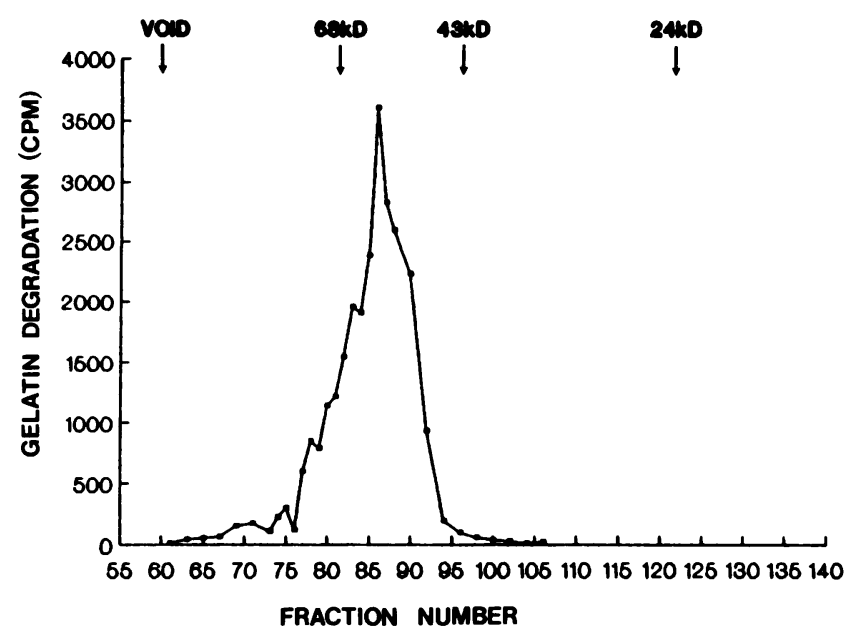

Figure 4. Gel chromatography of lipocyte gelatinase. Serum-free, lipocyte-conditioned media, collected between 2 and $6 \mathrm{~d}$ of primary culture were pooled (total volume $125 \mathrm{ml}$ ), concentrated 12.5-fold with polyethylene glycol (PEG, 40,000) and dialyzed against column buffer $\left(0.05 \mathrm{M}\right.$ Tris, pH 7.6, containing $0.2 \mathrm{M} \mathrm{NaCl}, 10 \mathrm{mM} \mathrm{CaCl}_{2}$, $0.02 \% \mathrm{NaN}_{3}$, and $0.05 \%$ Brij 35). This material was chromatographed at $4^{\circ} \mathrm{C}$ on a Sephacryl S200 superfine column $(90 \times 2.4 \mathrm{~cm})$ at a flow rate of $13.75 \mathrm{ml} / \mathrm{min}$, with collection of $2.75-\mathrm{ml}$ fractions. Individual fractions were assayed (after activation with APMA) for gelatinase activity, as in Table I. The Sephacryl S200 column was calibrated with BSA (68 kD), ovalbumin (43 kD), and chymotrypsinogen (24 kD).

dation of $\left[{ }^{14} \mathrm{C}\right]$ gelatin at $37^{\circ} \mathrm{C}$ is illustrated in Fig. 5. Relatively short-term incubation yielded multiple products of intermediate molecular weight. With increasing duration of incubation, the proportion of very low molecular weight products increased, indicating secondary cleavage of initial degradation products.

Degradation of collagen substrates was examined with collagen types I, IV, and V. Soluble native rat skin $\left[{ }^{14} \mathrm{C}\right]$ type I

Table II. Latent Proteinase Activation

\begin{tabular}{cc}
\hline \multicolumn{1}{c}{ Sample } & Gelatinase activity \\
\hline & \% of maximal activity \\
Nonactivated & 1 \\
+APMA & 100 \\
+Trypsin $(0.01 \mu \mathrm{g} / \mathrm{ml}, 60 \mathrm{~min})$ & 3 \\
+Trypsin $(0.10 \mu \mathrm{g} / \mathrm{ml}, 60 \mathrm{~min})$ & 2 \\
+Trypsin $(1.00 \mu \mathrm{g} / \mu \mathrm{l}, 60 \mathrm{~min})$ & 5 \\
+Trypsin $(1.00 \mu \mathrm{g} / \mu \mathrm{l}, 20 \mathrm{~min})$ & 2 \\
+Trypsin $(1.00 \mu \mathrm{g} / \mu \mathrm{l}, 5 \mathrm{~min})$ & 1 \\
\hline
\end{tabular}

Pooled column fractions containing the $65-\mathrm{kD}$ proteinase were assayed for gelatinase activity as described in the legend to Table I. Samples were assayed before or after exposure to APMA ( $1 \mathrm{mM}$ for $60 \mathrm{~min}$ at $37^{\circ} \mathrm{C}$ ) or trypsin at the indicated concentration and time, at $20^{\circ} \mathrm{C}$. A fivefold molar excess of soybean trypsin inhibitor was added to trypsin-treated samples before addition of the $\left[{ }^{14} \mathrm{C}\right]$ gelatin substrate. Higher concentrations of trypsin $(10$ and $100 \mu \mathrm{g} / \mathrm{ml}$, respectively) or incubation at $37^{\circ} \mathrm{C}$ failed to further activate the enzyme (data not shown). The activity of the native sample was 0.6 and for the APMA-treated sample was $42.9 \mathrm{mU} / 100 \mu \mathrm{l}$. 
Table III. Inhibition of APMA-activated Proteinase

\begin{tabular}{cc}
\hline \multicolumn{1}{c}{ Sample } & Gelatinase activity \\
\hline & $\%$ of control \\
Control & 100 \\
+EDTA $(10 \mathrm{mM})$ & 0 \\
+NEM $(2 \mathrm{mM})$ & 100 \\
+PMSF vehicle (isopropanol) & 100 \\
+PMSF $(1 \mathrm{mM})$ & 94 \\
\hline
\end{tabular}

Pooled column fractions containing the $65-\mathrm{kD}$ proteinase were assayed for gelatinase activity as described in the legend to Table I. Paired samples were assayed after exposure to APMA: the nonactivated samples in this experiment had no detectable activity; after APMA (control), the activity was $2.5-3.3 \mathrm{mU} / 100 \mu \mathrm{l}$.

collagen was not degraded by the $65-\mathrm{kD}$ proteinase at $25^{\circ} \mathrm{C}$ (Fig. $6 \mathrm{~A}$ ), in contrast to $\left[{ }^{14} \mathrm{C}\right]$ gelatin (Fig. $6 \mathrm{~B}$ ). Similar results were obtained with soluble native human amniotic ${ }^{125}$ I-type I collagen as substrate (Fig. 7). However, at 32 and $37^{\circ} \mathrm{C}$ (temperatures at which thermal denaturation of soluble type I collagen occurs, [16]), degradation was evident (Fig. 7). In addition, the substrate became susceptible to trypsin, indicating unfolding of the helix. Similarly, native human amniotic ${ }^{125} \mathrm{I}$ type $\mathrm{V}$ collagen was not degraded at $25^{\circ} \mathrm{C}$ but was attacked by both the $65-\mathrm{kD}$ proteinase and trypsin at 32 and $37^{\circ} \mathrm{C}$ (Fig. 7). (Thermal denaturation of soluble type $\mathrm{V}$ collagen is initiated at $30^{\circ} \mathrm{C}$ with a half-maximal temperature $\left[T_{\mathrm{m}}\right]$ of $33^{\circ} \mathrm{C}$ [39].) These results indicate that the proteinase is inactive against native collagen types $I$ and $V$, but that it will attack interstitial collagens that have been partially denatured.

In contrast to these results, the proteinase cleaved native murine ${ }^{125}$ I-type IV (basement membrane) collagen in a timedependent, EDTA-inhibitable manner at $30^{\circ} \mathrm{C}$ (Figs. 8 and 9). (Thermal denaturation of soluble type IV collagen is initiated at $33^{\circ} \mathrm{C}$, with a $T_{\mathrm{m}}$ of $40^{\circ} \mathrm{C}[40]$.) This is seen as disappearance

Table IV. Reversibility of EDTA Inhibition of Lipocyte Proteinase

\begin{tabular}{ccc}
\hline Proteinase sample & Added metal & Activity \\
\hline & & $\%$ control \\
APMA-activated & - & 100 \\
+5 mM EDTA & - & 1 \\
+0.5 mM EDTA & - & 2 \\
+0.1 mM EDTA & - & 5 \\
+0.01 mM EDTA & - & 14 \\
+0.1 mM EDTA & $\mathrm{Zn}(0.11 \mathrm{mM})$ & 41 \\
+0.1 mM EDTA & $\mathrm{Zn}(0.20 \mathrm{mM})$ & 92 \\
+0.1 mM EDTA & $\mathrm{Zn}(0.50 \mathrm{mM})$ & 30 \\
+0.1 mM EDTA & $\mathrm{Mn}(0.20 \mathrm{mM})$ & 52 \\
+0.1 mM EDTA & $\mathrm{Cu}(0.20 \mathrm{mM})$ & 32 \\
+0.1 mM EDTA & $\mathrm{Mg}(0.2 \mathrm{mM})$ & 6 \\
+0.1 mM EDTA & $\mathrm{Ca}(0.2 \mathrm{mM})$ & 7 \\
\hline
\end{tabular}

APMA, $1 \mathrm{mM}$; proteinase samples were activated with incubation at $37^{\circ} \mathrm{C}$ for $60 \mathrm{~min}$.

The enzyme preparation was the peak fraction from gel chromatography (see Fig. 4), in a buffer containing $5 \mathrm{mM}$ calcium.

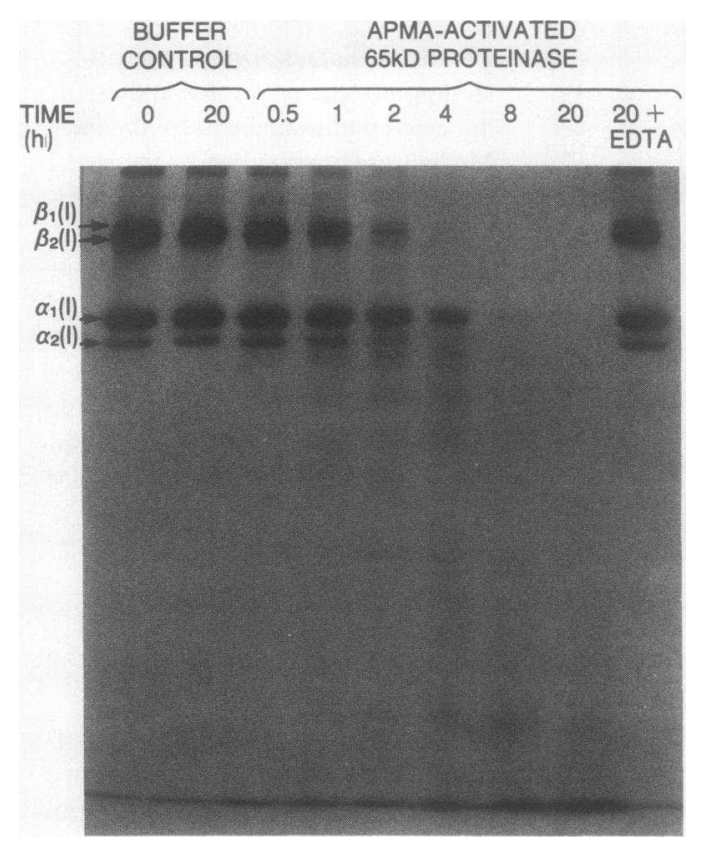

Figure 5. Analysis of $\left[{ }^{14} \mathrm{C}\right]$ gelatin degradation. Rat skin $\left[{ }^{14} \mathrm{C}\right]$ type $\mathrm{I}$ collagen was heat-denatured $\left(60^{\circ} \mathrm{C} \times 20 \mathrm{~min}\right)$ to form $\left[{ }^{14} \mathrm{C}\right]$ gelatin and incubated, at $37^{\circ} \mathrm{C}$, with APMA-treated buffer solution or APMA-activated pooled column fractions containing the $65-\mathrm{kD}$ proteinase (fractions 76-90, see Fig. 4). Each reaction contained $100 \mu \mathrm{g}$ of $\left[{ }^{14} \mathrm{C}\right]$ gelatin (specific activity, $350 \mathrm{cpm} / \mu \mathrm{g}$ ) and $5.5 \mathrm{mU}$ of gelatinase activity in a final volume of $200 \mu \mathrm{l}$. At the end of the reaction, 50 $\mu \mathrm{l}$ were mixed with sample buffer (38) containing 2-mercaptoethanol and electrophoresed on a $7.5 \%$ polyacrylamide gel. An autoradiogram of the gel is shown.

of the alpha-1-(IV) and alpha-2-(IV) bands, together with the appearance of cleavage products of $M_{\mathrm{r}} 125$ and $92 \mathrm{kD}$ (Fig. 8). Degradation was detectable also at $25^{\circ} \mathrm{C}$ with formation of the same molecular size cleavage products, and was inhibited by EDTA (Figs. 8 and 9). At $37^{\circ} \mathrm{C}$, (conditions that initiate thermal denaturation of soluble type IV collagen) degradation of the ${ }^{125}$ I-type IV collagen substrate was accelerated and yielded products of different molecular size (Fig. 9). The sensitivity of native ${ }^{125} \mathrm{I}$-type IV collagen to trypsin $(10 \mu \mathrm{g} / \mathrm{ml} \times 20 \mathrm{~h})$ was also temperature dependent; limited cleavage was observed at 25 and $30^{\circ} \mathrm{C}$, consistent with previous reports of the sensitivity of the native molecule to proteolytic digestion (33, 40-42). By contrast, trypsin-mediated degradation was extensive at $37^{\circ} \mathrm{C}$. These results indicate that type IV collagen in its native conformation is degraded by the $65-\mathrm{kD}$ proteinase. The additional and more extensive degradation at $37^{\circ} \mathrm{C}$ presumably reflects thermal denaturation of the substrate.

\section{Discussion}

Hepatic lipocytes (fat-storing, stellate, perisinusoidal, or Ito cells) are located in the subendothelial space of Disse. In normal liver, they exhibit long cellular processes that encircle the sinusoid (43). They also store vitamin A esters in vacuoles (43, 44). In models of acute liver injury, lipocyte proliferation is prominent in areas of necrosis (45-50) where deposition of new matrix proteins is occurring (51). This morphologic evidence suggests an important role for lipocytes in liver fibrosis and is supported by findings from cell culture. Lipocytes, ob- 


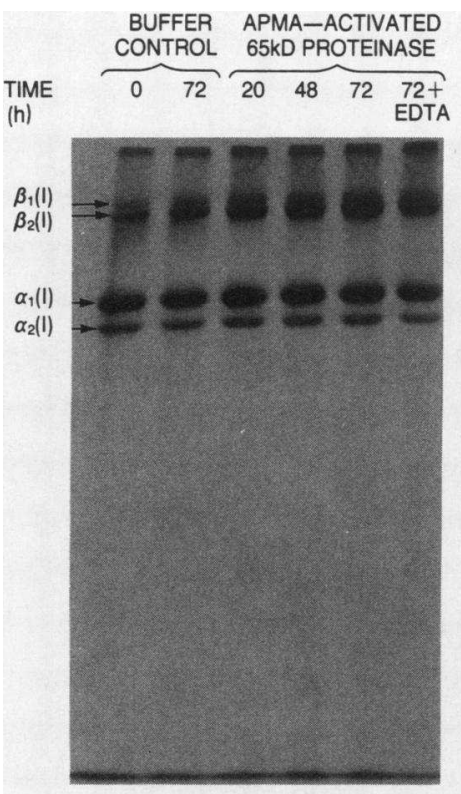

A. NATIVE TYPE I COLLAGEN
APMA-ACTIVATED

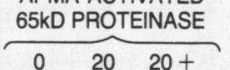

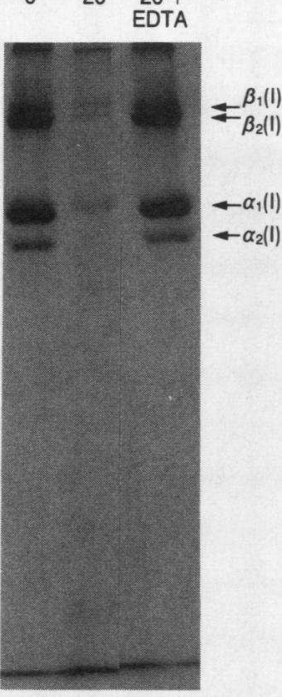

B. GELATIN

Figure 6. Analysis of type I collagen degradation. Pooled column fractions, processed and activated as in Fig. 5, were incubated at $25^{\circ} \mathrm{C}$, with either native rat skin $\left[{ }^{14} \mathrm{C}\right]$ type I collagen (Fig. $6 \mathrm{~A}$ ) or the same substrate that had been heat-denatured $\left(60^{\circ} \mathrm{C} \times 20 \mathrm{~min}\right.$ ) (Fig. $6 \mathrm{~B})$. Reactions with native $\left[{ }^{14} \mathrm{C}\right]$ type I collagen were performed in the presence of $0.25 \mathrm{M}$ glucose to inhibit fibril formation. For both substrates each reaction contained $5.5 \mathrm{mU}$ of gelatinase activity and $100 \mu \mathrm{g}$ of $\left[{ }^{14} \mathrm{C}\right]$ gelatin or $\left[{ }^{14} \mathrm{C}\right]$ type I collagen in a final volume of 200 $\mu$ l. At the end of the reaction, samples were analyzed as in Fig. 5. Buffer controls for the gelatin substrate (not shown) were identical to those shown in Fig. 5. An autoradiogram is shown.

tained from normal rat liver and studied in primary culture, are a major source of liver matrix proteins including collagens $(24)$, laminin $(25)$, and proteoglycans $(26,52)$ and fibronectin (53).

These results indicate that lipocytes may be involved in matrix turnover as well as its synthesis. Assignment of the 65-kD proteinase to lipocytes is based on the fact that the cultures are $>99 \%$ pure. We cannot exclude that Kupffer cells also produce this proteinase in small amounts. However, their principal product, as visualized on gelatin substrate gels, is a proteinase of $95 \mathrm{kD}$, which is similar in size and possibly related to enzymes secreted by alveolar macrophages (54) and neutrophils (55-58).

Two aspects of the experimental results bear on the regulation of proteinase activity. The first is that the proteinase secreted by lipocytes is almost entirely latent, as is typical of neutral metalloproteinases. The question of proteinase activation in vivo is an important one and still not settled. Stromelysins may have this role (59) and are secreted by mesenchymal cells (60-63). However, we found no activity of this type (as judged by casein degradation) in the medium from lipocyte cultures. It may be produced in situ by a second cell type. Also, membrane-associated proteinases have been described in rat liver (64). The second is batch-to-batch variation in proteinase secretion by the cultured lipocytes. We were unable to relate this to cell density, the age of the culture, the presence of Kupffer cells, or the assay itself. Within a single batch of cells, variation in the assay was acceptably small $(<10 \%)$, indicating its reproducibility. One possibility is that culturing per se (e.g., contact with plastic) induces varying degrees of lipocyte stimulation. Proteinase production by other cells is modulated by extracellular matrix (65). Studies of the regulation of lipocyte

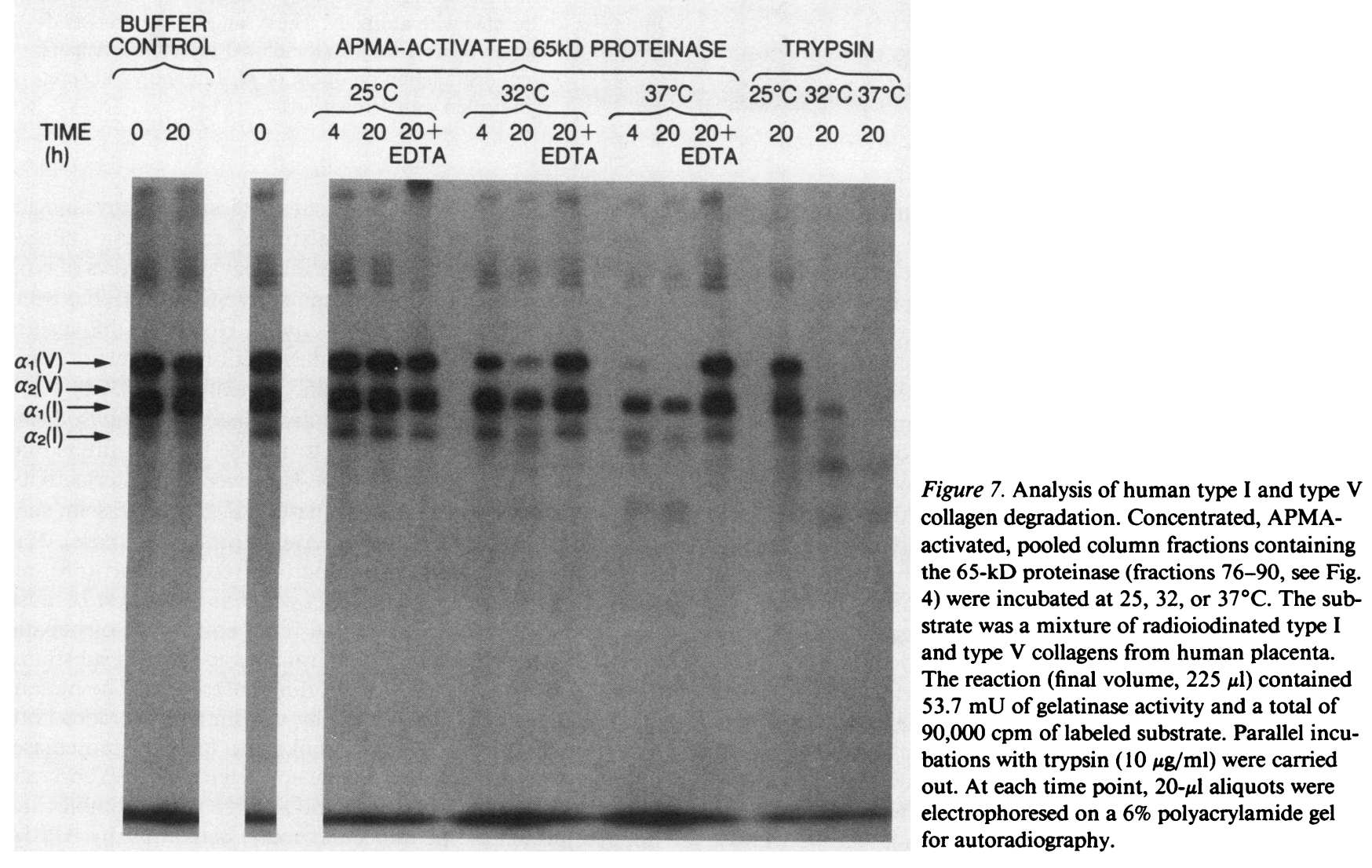




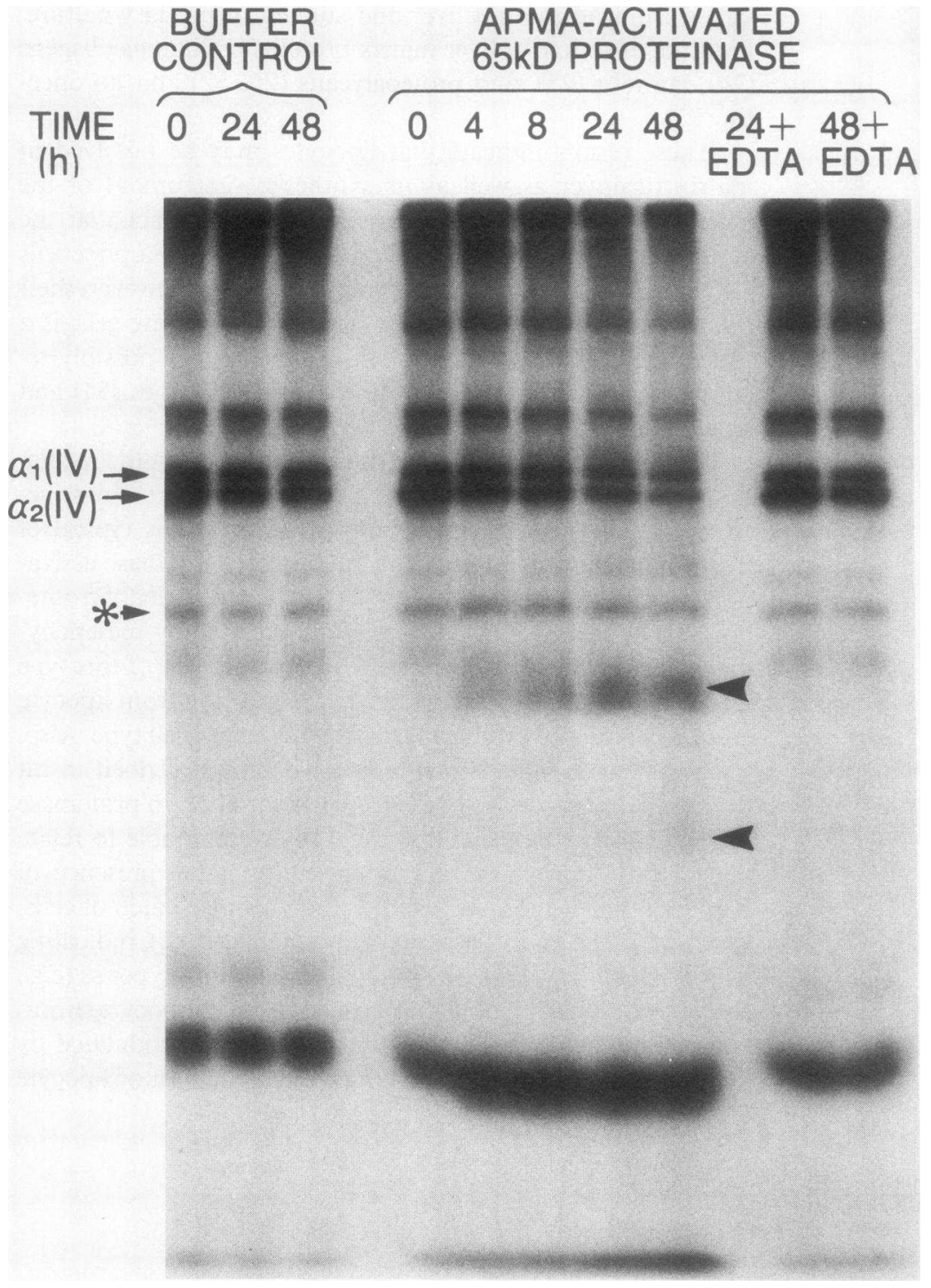

Figure 8. Analysis of type IV collagen degradation. Concentrated, APMA-activated, pooled column fractions containing the $65-\mathrm{kD}$ proteinase were incubated at $30^{\circ} \mathrm{C}$, in a reaction containing $257 \mathrm{mU}$ of gelatinase activity and $80,000 \mathrm{cpm}$ of iodinated type IV collagen in a final volume of $140 \mu \mathrm{l}$. At the indicated time points, $15-\mu l$ aliquots were electrophoresed on a $6 \%$ gel for autoradiography. In preliminary studies the substrate was evaluated by immunoblot with an affinity purified antibody to type IV collagen (4). All iodinated bands except that marked with an asterisk reacted with antibody. These same bands decreased upon incubation with the $65-\mathrm{kD}$ proteinase. Apparent degradation products, of $M_{\mathrm{r}} 125$ and $92 \mathrm{kD}$ are indicated with arrowheads. proteinase production will be an important goal of further studies.

Several early studies of liver proteinases focused almost exclusively on interstitial collagenase, using type I collagen as substrate $(17,18)$, and none clearly identified cellular sources. Activity attributed to hepatocytes could have derived from lipocytes in view of recent evidence that the latter cell type is present within hepatocyte cultures constituting up to $10 \%$ of the total cell number (66). A second methodological concern is that, although most studies were designed to detect interstitial collagenases, many used assay conditions that fail to distinguish collagenase from gelatinase activity and must be reevaluated in light of the present evidence that lipocytes release a gelatin-degrading neutral metalloproteinase. The methods commonly employed to measure collagenase activity (reconstituted and diffuse fibril assays, or methods that use soluble type I collagen as substrate [16]) have notoriously high values for nonspecific (e.g., trypsin-mediated) degradation of the substrate. The temperature at which reactions are performed is particularly important (67). Type I collagen in solution is susceptible to nonspecific proteolysis $>30^{\circ} \mathrm{C}$, whereas the corresponding temperature for fibril assays is $35-37^{\circ} \mathrm{C}$. Thus, assays carried out with soluble substrate and at 'physiologic' temperatures may measure a gelatinase, rather than collagenase. A demonstration of the specific cleavage products of type I collagen (TCA and TCB fragments) by SDS-PAGE has been assumed to verify collagenase activity. However, this also is subject to misinterpretation, as degradation products of similar size may occur with nonspecific proteolysis (16).

Granuloma cells derived from Schistosoma mansoni-infested murine liver were found to release both an interstitial collagenase and a gelatinase (22). However, the latter activity differed from the lipocyte proteinase in degrading casein, suggesting that it may be a stromelysin (proteoglycanase). Rat kidney mesangial cells, according to a recent report (68), release a neutral metalloproteinase, which is of interest because these mesenchymal cells are the renal equivalent of hepatic lipocytes. Although the molecular mass and range of substrates for the two enzymes are similar, differences exist. The mesangial cell proteinase is activated by trypsin and degrades both casein and type $\mathrm{V}$ collagen, unlike the lipocyte proteinase. Oncogene-transformed bronchial epithelial cells (69) and rabbit bone cultures (70) secrete an activity that resembles the lipocyte proteinase in molecular mass, activation by APMA 


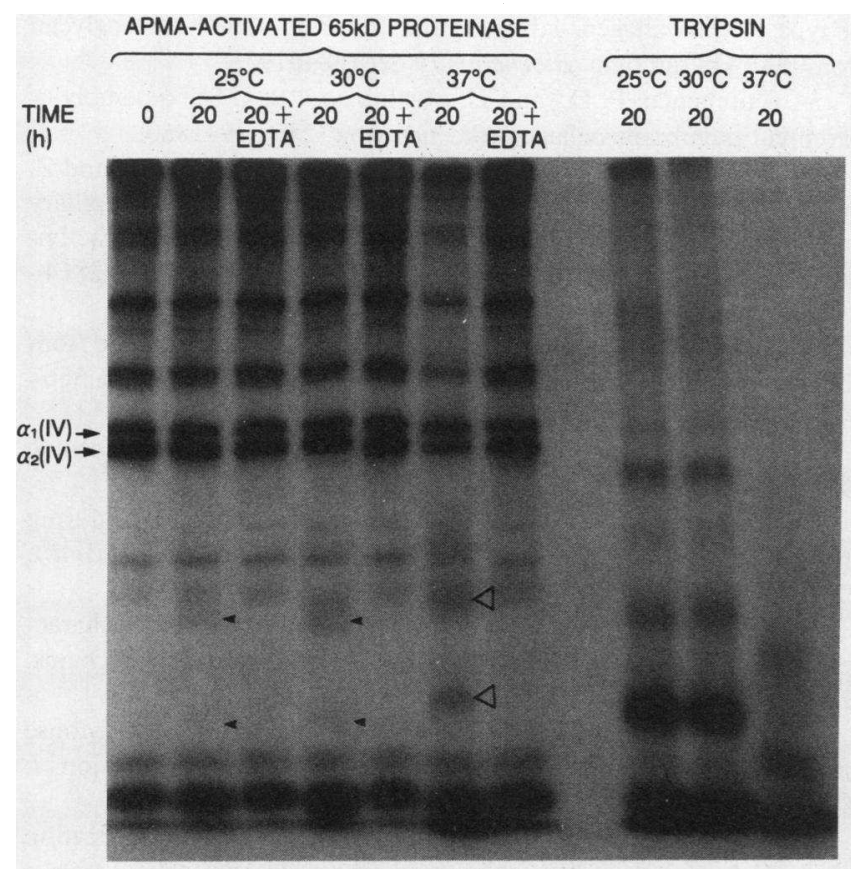

Figure 9. Concentrated, APMA-activated, column fractions containing the $65-\mathrm{kD}$ proteinase or trypsin $(10 \mu \mathrm{g} / \mu \mathrm{l})$ were incubated at 25 , 30 , and $37^{\circ} \mathrm{C}$ with native soluble ${ }^{125} \mathrm{I}$-type IV collagen. The initial reaction mixture contained $36 \mathrm{mU}$ of gelatinase activity and 31,500 $\mathrm{cpm}$ of labeled substrate in a final volume of $210 \mu \mathrm{l}$. At each time point, 30- $\mu 1$ aliquots were reduced and electrophoresed on a 5\% SDSpolyacrylamide gel for autoradiography. Reaction products obtained at 25 and $30^{\circ} \mathrm{C}$ are marked with small arrowheads. Different molecular size products, obtained at $37^{\circ} \mathrm{C}$, are marked with large arrowheads.

but not by trypsin, and sensitivity to sulfhydryl reduction (70). The range of substrates degraded also is essentially identical. A minor difference is the fact that rabbit bone gelatinase appeared to have low activity against casein and type $V$ collagen, whereas lipocyte proteinase did not degrade casein and attacked type $\mathrm{V}$ collagen only at temperatures $\left(32\right.$ and $\left.37^{\circ} \mathrm{C}\right)$ associated with partial denaturation.

Proteinases with similar substrate specificity have been shown to attack intact basement membranes $(71,72)$. The lipocyte proteinase, with activity against native basement membrane (type IV) collagen, may be involved in the initiation of matrix degradation in the liver. In current models of the basement membrane, the principal collagen is type IV, which forms the core of the complex (34). Recent work from this and other laboratories has demonstrated the importance of a basement membrane-like complex in the maintenance of differentiated function of hepatocytes (4-6). These studies have shown, moreover, that the entire matrix complex is required: individual purified matrix proteins (type IV collagen, laminin, fibronectin) fail to sustain the expression of hepatocyte-specific functions (4). These data support the concept that the quaternary structure of the subendothelial matrix is critical to its biologic role. Thus, degradation of a single component, such as type IV collagen, may alter the matrix structure sufficiently to have pathologic effects. Also, matrix production by lipocytes is regulated by the extracellular matrix itself: lipocytes cultured on a basement membrane-like substratum are strikingly more quiescent than are cells on individual matrix proteins or on plastic (3). Alteration of the matrix may cause activation of lipocytes to a proliferating and fibrogenic mode. Such a phenomenon could contribute to the progression of fibrosis that occurs in the apparent absence of the original pathogenic factor (73).

In conclusion, these studies describe a mechanism for the degradation of basement-membrane matrix, mediated by hepatic lipocytes. They point the way to examining production of this proteinase in the intact liver, in order to define its role in hepatic inflammation and fibrosis.

\section{Acknowledgments}

We are grateful for helpful advice from Dr. Michael J. Banda, technical assistance from Glenn Yamasaki, and manuscript preparation by Anne Copi and Janet Doherty.

M. J. P. Arthur was supported by an International Postdoctoral Fellowship (FO5 TWO3726) from the U. S. National Institutes of Health (NIH), by funds from the Medical Research Council of Great Britain, the American Liver Foundation, and the Smith and Nephew Foundation of Great Britain. Partial support was provided also by grants from the NIH (DK-31 198, IP50-DK-26743, DK-37340) and the National Institute of Alcohol Abuse and Alcoholism (AA 06092).

\section{References}

1. Timpl, R., and G. R. Martin. 1982. Components of basement membranes. In Immunochemistry of the Extracellular Matrix. $\mathrm{H}$. Furthmayr, editor. CRC Press, Boca Raton, FL. 119-150.

2. Aplin, J. D., and R. C. Hughes. 1982. Complex carbohydrates of the extracellular matrix. Structures, interactions and biological roles. Biochim. Biophys. Acta. 694:375-418.

3. Friedman, S. L., F. J. Roll, J. S. Boyles, D. M. Arenson, and D. M. Bissell. 1989. Maintenance of differentiated phenotype of cultured rat lipocytes by basement membrane matrix. J. Biol. Chem. 264:10756-10762.

4. Bissell, D. M., D. M. Arenson, J. J. Maher, and F. J. Roll. 1987. Support of cultured hepatocytes by a laminin-rich gel. Evidence for a functionally significant subendothelial matrix in normal rat liver. $J$. Clin. Invest. 79:801-812.

5. Ben-Ze'ev, A., G. S. Robinson, N. L. R. Bucher, and S. R. Farmer. 1988. Cell-cell and cell-matrix interactions differentially regulate the expression of hepatic and cytoskeletal genes in primary cultures of rat hepatocytes. Proc. Natl. Acad. Sci. USA. 85:2161-2165.

6. Schuetz, E. G., D. Li, C. J. Omiecinski, U. Muller-Eberhard, H. K. Kleinman, B. Elswick, and P. S. Guzelian. 1988. Regulation of gene expression in adult rat hepatocytes cultured on a basement membrane matrix. J. Cell. Physiol. 134:309-323.

7. Popper, H., and S. Udenfriend. 1970. Hepatic fibrosis. Correlation of biochemical and morphologic investigations. Am. J. Med. 49:707-721.

8. Orrego, H., A. Medline, L. M. Blendis, J. G. Rankin, and D. A. Kreaden. 1979. Collagenisation of the Disse space in alcoholic liver disease. Gut. 20:673-679.

9. Maruyama, K., L. Feinman, Z. Fainsilber, M. Nakano, I. Okazaki, and C. S. Lieber. 1982. Mammalian collagenase increases in early alcoholic liver disease and decreases with cirrhosis. Life Sci. 30:13791384.

10. Lindblad, W. J., and G. C. Fuller. 1983. Hepatic collagenase activity during carbon tetrachloride induced fibrosis. Fundam. Appl. Toxicol. 3:34-40.

11. Hasty, K. A., M. S. Hibbs, A. H. Kang, and C. L. Mainardi. 1986. Secreted forms of human neutrophil collagenase. J. Biol. Chem. 261:5645-5650. 
12. Okazaki, I., and K. Maruyamo. 1974. Collagenase activity in experimental hepatic fibrosis. Nature (Lond.). 252:49-50.

13. Montfort, I., and R. Perez-Tamayo. 1978. Collagenase in experimental carbon tetrachloride cirrhosis of the liver. Am. J. Pathol. 92:411-419.

14. Carter, E. A., M. J. McCarron, E. Alpert, and K. J. Isselbacher. 1982. Lysyl oxidase and collagenase in experimental acute and chronic liver injury. Gastroenterology. 82:526-534.

15. Perez-Tamayo, R., I. Montfort, and E. Gonzalez. 1987. Collagenolytic activity in experimental cirrhosis of the liver. Exp. Mol. Pathol. 47:300-308.

16. Birkedale-Hansen, H. 1987. Catabolism and turnover of collagens: collagenases. Methods Enzymol. 144:140-171.

17. Fujiwara, K., T. Sakai, T. Oda, and S. Igarashi. 1973. The presence of collagenase in Kupffer cells of the rat liver. Biochem. Biophys. Res. Commun. 54:531-537.

18. Bhatnagar, R., U. Schade, E. Th. Rietschel, and K. Decker. 1982. Involvement of prostaglandin $E$ and adenosine 3',5'-monophosphate in lipopolysaccharide-stimulated collagenase release by rat Kupffer cells. Eur. J. Biochem. 125:125-130.

19. Nagai, Y., H. Hori, R. I. Hata, H. Konomi, and H. Sunada. 1982. Collagenase production by adult rat hepatocytes in primary culture. Biomed. Res. 3:345-349.

20. Maruyama, K., I. Okazaki, T. Kobayashi, H. Suzuki, K. Kashiwazaki, and M. Tsuchiya. 1983. Collagenase production by rabbit liver cells in monolayer culture. J. Lab. Clin. Med. 102:543-550.

21. Kashiwazaki, K., M. S. Hibbs, J. M. Seyer, C. L. Mainardi, and A. H. Kang. 1986. Stimulation of interstitial collagenase in co-cultures of rat hepatocytes and sinusoidal cells. Gastroenterology. 90:829-836.

22. Takahashi, S., and E. Simpser. 1981. Granuloma collagenase and EDTA-sensitive neutral protease production in hepatic murine schistosomiasis. Hepatology (Baltimore). 1:211-220.

23. Friedman, S. L., and F. J. Roll. 1987. Isolation and culture of hepatic lipocytes, Kupffer cells, and sinusoidal endothelial cells by density gradient centrifugation with stractan. Anal. Biochem. 161:207-218.

24. Friedman, S. L., J. F. Roll, J. Boyles, and D. M. Bissell. 1985. Hepatic lipocytes: the principal collagen-producing cells of normal rat liver. Proc. Natl. Acad. Sci. USA. 82:8681-8685.

25. Maher, J. J., S. L. Friedman, F. J. Roll, and D. M. Bissell. 1988. Immunolocalization of laminin in normal rat liver and biosynthesis of laminin by hepatic lipocytes in primary culture. Gastroenterology. 94:1053-1062.

26. Arenson, D. M., S. L. Friedman, and D. M. Bissell. 1988. Formation of extracellular matrix in normal rat liver: lipocytes as a major source of proteoglycan. Gastroenterology. 95:441-447.

27. Arthur, M. J. P., P. Kowalski-Saunders, and R. Wright. 1986. Corynebacterium parvum-elicited hepatic macrophages demonstrate enhanced respiratory burst activity compared with resident Kupffer cells in the rat. Gastroenterology. 89:1114-1122.

28. Irving, M. G., F. J. Roll, S. Huang, and D. M. Bissell. 1984. Characterization and culture of sinusoidal endothelium from normal rat liver: lipoprotein uptake and collagen phenotype. Gastroenterology. 87:1233-47.

29. Cawston, T. E., and A. J. Barrett. 1979. A rapid and reproducible assay for collagenase using $\left[1-{ }^{14} \mathrm{C}\right]$ acetylated collagen. Anal. Biochem. 99:340-345.

30. Burgeson, R. E., F. A. El Adli, I. I. Kaitila, and D. W. Hollister. 1976. Fetal membrane collagens: identification of two new collagen alpha chains. Proc. Natl. Acad. Sci. USA. 73:2579-2583.

31. Madri, J. A., and H. Furthmayr. 1979. Isolation and tissue localization of type AB2 collagen from normal lung parenchyma. Am. J. Pathol. 94:323-330.

32. Roll, F. J., J. A. Madri, and H. Furthmayr. 1979. A new method of iodinating collagen for use in radioimmunoassay. Anal. Biochem. 96:489-499.

33. Kleinman, H. K., M. L. McGarvey, L. A. Liotta, P. G. Robey, K. Tryggvason, and G. R. Martin. 1982. Isolation and characterization of type IV procollagen, laminin, and heparan sulfate proteoglycan from the EHS sarcoma. Biochemistry. 2:6188-6193.

34. Yurchenco, P. D., and H. Furthmayr. 1984. Self-assembly of basement membrane collagen. Biochemistry. 23:1839-1850.

35. Herron, G. S., M. J. Banda, E. J. Clark, J. Gavrilovic, and Z. Werb. 1986. Secretion of metalloproteinases by stimulated capillary endothelial cells. II. Expression of collagenase and stromelysin activities is regulated by endogenous inhibitors. J. Biol. Chem. 261:28142818.

36. Harris, E. D., and S. M. Krane. 1972. An endopeptidase from rheumatoid synovial tissue culture. Biochim. Biophys. Acta. 258:566576.

37. Labarca, C., and K. Paigen. 1980. A simple, rapid and sensitive DNA assay procedure. Anal. Biochem. 102:344-352.

38. Laemmli, U. K. 1970. Cleavage of structural proteins during the assembly of the head of bacteriophage T4. Nature (Lond.). 227:680-685.

39. Rhodes, R. K., and E. J. Miller. 1978. Physicochemical characterization and molecular organization of the collagen A and B chains. Biochemistry. 17:3442-3448.

40. Bachinger, H. P., L. I. Fessler, and J. H. Fessler. 1982. Mouse procollagen IV. Characterization and supramolecular organization. $J$. Biol. Chem. 257:9796-9803.

41. Timpl, R., P. Bruckner, and P. Fietzek. 1979. Characterization of pepsin fragments of basement membrane collagen obtained from a mouse tumor. Eur. J. Biochem. 95:253-263.

42. Tryggvason, K., P. G. Robey, and G. R. Martin. 1980. Biosynthesis of type IV procollagens. Biochemistry. 19:1284-1289.

43. Wake, K. 1980. Perisinusoidal stellate cells (fat-storing cells, interstitial cells, lipocytes), their related structure in and around the liver sinusoids, and vitamin A-storing cells in extrahepatic organs. Int. Rev. Cytol. 66:303-353.

44. Hendriks, H. F. J., A. Brouwer, and D. L. Knook. 1987. The role of hepatic fat-storing (stellate) cells in retinoid metabolism. Hepatology (Baltimore). 7:1368-1371.

45. McGee, J. O., and R. S. Patrick. 1972. The role of perisinusoidal cells in hepatic fibrogenesis. An electron microscopic study of acute carbon tetrachloride liver injury. Lab. Invest. 26:429.

46. Kent, G., S. Gay, T. Inouye, R. Bahu, O. T. Minick, and H. Popper. 1976. Vitamin-A-containing lipocytes and formation of type III collagen in liver injury. Proc. Natl. Acad. Sci. USA. 73:3719-3722.

47. Minato, Y., Y. Hasumura, and J. Takeuchi. 1983. The role of fat-storing cells in the Disse space fibrogenesis in alcoholic liver disease. Hepatology (Baltimore). 3:559-566.

48. Okanoue, T., E. J. Burbige, and S. W. French. 1983. The role of the Ito cell in perivenular and intralobular fibrosis in alcoholic hepatitis. Arch. Pathol. Lab. Med. 107:459-463.

49. Yokoi, Y., T. Namihisa, K. Matsuzaki, A. Miyazaki, and Y. Yamaguchi. 1988. Distribution of Ito cells in experimental liver fibrosis. Liver. 8:48-52.

50. Burt, A. D., J. L. Robertson, J. Heir, and R. N. M. Macsween 1986. Desmin-containing stellate cells in rat liver: distribution in normal animals and response to experimental acute liver injury. J. Pathol. 150:29-35.

51. Ogawa, K., J.-I. Suzuki, H. Mukai, and M. Mori. 1986. Sequential changes of extracellular matrix and proliferation of Ito cells with enhanced expression of desmin and actin in focal hepatic injury. Am. J. Pathol. 125:611-619.

52. Schaefer, S., O. Zerbe, and A. M. Gressner. 1987. The synthesis of proteoglycans in fat-storing cells of rat liver. Hepatology (Baltimore). 7:680-687.

53. Ramadori, G., H. Rieder, Th. Knittel, H. P. Dienes, and K. Meyer zum Buschenfelde. 1987. Fat-storing cells (FSC) of rat liver synthesize and secrete fibronectin. J. Hepatol. (Amst.). 4:190-197.

54. Hibbs, M. S., J. R. Hoidal, and A. H. Kang. 1987. Expression of a metalloproteinase that degrades native type $\mathrm{V}$ collagen and denatured collagens by cultured human alveolar macrophages. J. Clin. Invest. 80:1644-1650. 
55. Sopata, I., and A. M. Dancewicz. 1974. Presence of a gelatinspecific proteinase and its latent form in human leucocytes. Biochim. Biophys. Acta. 370:510-523.

56. Sopata, I. 1982. Further purification and some properties of a gelatin-specific proteinase of human leucocytes. Biochim. Biophys. Acta. 717:26-31.

57. Murphy, G., J. J. Reynolds, U. Bretz, and M. Baggiolini. 1982. Partial purification of collagenase and gelatinase from human polymorphonuclear leucocytes. Biochem. J. 203:209-221.

58. Hibbs, M. S., K. A. Hasty, J. A. Seyer, A. H. Kang, and C. L. Mainardi. 1985. Biochemical and immunological characterization of the secreted forms of human neutrophil gelatinase. J. Biol. Chem. 260:2493-2500.

59. Murphy, G., M. I. Cockett, P. E. Stephens, B. J. Smith, and A. J. P. Docherty. 1987. Stromelysin is an activator of procollagenase. Biochem. J. 248:265-268.

60. Wilhelm, S. M., I. E. Collier, A. Kronberger, A. Z. Eisen, B. L. Marmer, G. A. Grant, E. A. Bauer, and G. I. Goldberg. 1987. Human skin fibroblast stromelysin: structure, glycosylation, substrate specificity, and differential expression in normal and tumorigenic cells. Proc. Natl. Acad. Sci. USA. 84:6725-6729.

61. Sellers, A., J. J. Reynolds, and M. C. Meikle. 1978. Neutral metalloproteinases of rabbit bone. Separation in latent forms of distinct enzymes that when activated degrade collagen, gelatin and proteoglycans. Biochem. J. 171:493-496.

62. Vaes, G., Y. Eeckhout, G. Lenaers-Claeys, C. Francois-Gillet, and J. E. Druetz. 1978. The simultaneous release by bone explants in culture and the parallel activation of procollagenase and of a latent neutral proteinase that degrades cartilage proteoglycans and denatured collagen. Biochem. J. 172:261-274.

63. Galloway, A., G. Murphy, J. D. Sandy, J. Gavrilovic, T. E. Cawston, and J. J. Reynolds. 1983. Purification and characterization of a rabbit bone metalloproteinase that degrades proteoglycan and other connective-tissue components. Biochem. J. 209:741-752.

64. Tanaka, K., T. Nakamura, and A. Ichihara. 1986. A unique trypsin-like protease associated with plasma membranes of rat liver. $J$. Biol. Chem. 261:2610-2615.

65. Turpeehniemi-Hujanen, T., U. P. Thorgeirsson, C. N. Rao, and L. A. Liotta. 1986. Laminin increases the release of type IV collagenase from malignant cells. J. Biol. Chem. 261:1883-1889.

66. Maher, J. J., D. M. Bissell, S. L. Friedman, and F. J. Roll. 1988. Collagen measured in primary cultures of normal rat hepatocytes derives from lipocytes within the monolayer. J. Clin. Invest. 82:450-459.

67. Ryhanen, L., E. J. Zaragoza, and J. Utto. 1983. Conformational stability of type I collagen triple helix: evidence for temporary and local relaxation of the protein conformation using a proteolytic probe. Arch. Biochem. Biophys. 223:562-571.

68. Davies, M., D. J. Thomas, J. Martin, and D. H. Lovett. 1988. The purification and characterization of glomerular-basement-degrading neutral proteinase from rat mesangial cells. Biochem. J. 251:419-425.

69. Collier, I. E., S. M. Wilhelm, A. Z. Eisen, B. L. Marmer, G. A. Grant, J. L. Seltzer, A. Kronberger, C. He, E. A. Bauer, and G. J. Goldberg. 1988. H-ras oncogene-transformed human bronchial epithelial cells (TBE-1) secrete a single metalloprotease capable of degrading basement membrane collagen. J. Biol. Chem. 263:6579-6587.

70. Murphy, G., C. G. McAlpine, C. T. Poll, and J. J. Reynolds. 1985. Purification and characterization of a bone metalloproteinase that degrades gelatin and types IV and V collagen. Biochim. Biophys. Acta. 831:49-58.

71. Bejarano, P. A., M. E. Noelken, K. Suzuki, B. G. Hudson, and H. Nagase. 1988. Degradation of basement membranes by human matrix metalloproteinase 3 (stromelysin). Biochem. J. 256:413-419.

72. Baricos, W. H., G. Murphy, Y. Zhou, H. H. Nguyen, and S. V. Shah. 1988. Degradation of glomerular basement membrane by purified mammalian metalloproteinases. Biochem. J. 254:609-612.

73. Marshall, J. B., D. A. Burnett, R. K. Zetterman, and M. F. Sorrell. 1983. Clinical and biochemical course of alcoholic liver disease following sudden discontinuation of alcoholic consumption. Alcoholism (Zagreb.). 7:312-315. 